\title{
REFLEXÕES SOBRE A CONSTRUÇ̃̃O DA PARENTALIDADE E O USO DE ESTRATÉGIAS EDUCATIVAS EM FAMÍLIAS DE BAIXO NÍVEL SOCIOECONÔMICO'
}

\author{
Laura Alonso de Bem \\ Adriana Wagner"
}

\begin{abstract}
RESUMO. Este artigo apresenta uma revisão da literatura sobre questões relativas à parentalidade à luz da Teoria EcológicoSistêmica, objetivando descrever alguns dos fatores que estão envolvidos no processo de escolha das estratégias educativas utilizadas por pais e mães de famílias de baixo nível socioeconômico. Identificamos os conceitos de valores, metas e práticas educativas e descrevemos as interconexões destes a partir de pesquisas empíricas que discutem as variáveis a serem consideradas no processo educativo. Partimos da premissa de que a forma de pensar e a forma de promover o desenvolvimento e a educação das crianças são construídas na relação com o contexto socioeconômico-cultural no qual as famílias estão inseridas. Concluímos que é fundamental podermos pensar nas idiossincrasias do meio em que vivem as famílias de camadas populares, pois elas refletem e são refletidas nos padrões de interação que se estabelecem entre os seus membros.
\end{abstract}

Palavras-chave: famílias de baixo nível socioeconômico, parentalidade, práticas educativas.

\section{REFLEXIONS ON PARENTHOOD AND EDUCATIVE STRATEGIES IN FAMILIES WITH LOW SOCIOECONOMIC STATUS}

\begin{abstract}
This article presents a literature review on issues about parenthood based on Ecological-System Theory, aiming at to describe some of the factors that are involved in the setting of goals and practices used by mothers and fathers from families of low socioeconomic status. We identify the concepts of educational values, goals and practices and describe their interconnections presented in empirical researches which examine the variables to be considered in the educational process. We have started from the premise that the way to think and promote children's development and education is constructed in relation to the socioeconomic and cultural context in which the families are inserted. We have concluded that is fundamental to think about the idiosyncrasies of the milieu in which low socioeconomic status families live, since they reflect and are reflected in the interaction patterns established among their members.
\end{abstract}

Key words: Low socioeconomic status families, parental values, child-rearing practices.

A gestação de um bebê é um período cheio de expectativas, em que a família se prepara para a chegada do novo membro. Cada criança que chega ao mundo não se incorpora a um contexto vazio, muito pelo contrário, nasce em um contexto familiar repleto de expectativas, crenças, valores e metas. Este cenário familiar forma um conjunto de influências que contribuirão na formação dos indivíduos, constituindose numa peça essencial para entender $o$ desenvolvimento desses indivíduos. Nesta perspectiva, é consensual entre os estudiosos do tema considerar a família como o primeiro e mais importante contexto de socialização (Hernandéz, Rodríguez, \& Zamora, 1998; MacCoby, 1984; Smith, 1982; Tudge, Hayes, Doucet, Kulakova, Tammeveski, Meltsas, \& Lee, 2000a).

Com base nessa premissa, muitos estudos têm sido feitos procurando compreender como se constrói no seio da família o processo educativo de socialização da criança. Entretanto, são escassas as pesquisas na área da Psicologia que se referem às famílias de baixo nível socioeconômico, mais

1 Apoio Capes.

* Mestre em Psicologia Social pela Pontifícia Universidade Católica do Rio Grande do Sul (PUCRS) com bolsa Capes, psicóloga comunitária da ACM (Associação Cristã de Moços) de Porto Alegre.

\# Doutora em Psicologia pela Universidad Autônoma de Madrid. Professora da Faculdade de Psicologia da Pontifícia Universidade Católica do Rio Grande do Sul (PUCRS) com dedicação exclusiva, bolsista CNPq. 
especificamente as brasileiras. Assim sendo, este artigo apresenta uma revisão da literatura sobre esta temática, à luz da Teoria Ecológico-Sistêmica (Bronfenbrenner, 1979/1996), buscando descrever alguns dos fatores que estão envolvidos no processo de escolha das estratégias educativas utilizadas por pais e mães de famílias da camada popular.

\section{O PROCESSO EDUCATIVO: DEFINIDO CONCEITOS}

Dentre as tarefas que compõem a função parental, provavelmente a educação dos filhos seja a mais complexa. O processo educativo normalmente se alicerça em determinados valores que pais e mães transmitem e procuram que seus filhos internalizem e assumam. Esta transmissão que se dá de geração a geração é essencial, pois, conforme Rokeach (1973) já assinalava na década de 1970, os valores orientam, são guias e determinantes do comportamento, sendo fundamentais para entender o modo como as pessoas situam-se perante si mesmas e os demais. Sendo assim, as relações interpessoais que o indivíduo passa a estabelecer ao longo da vida também são decorrentes desse processo. Dessa forma, pode-se observar que pais e mães procuram agir para que seus filhos adquiram os valores familiares, ainda que não o façam de forma consciente.

Existe uma estreita relação entre valores e metas familiares, os quais muitas vezes são definidos da mesma forma na literatura. Ceballos e Rodrigo (1998) explicam essa associação e afirmam que os valores constituem-se em verdadeiras metas que os progenitores perseguem para seus filhos.

Neste sentido, Melvin Kohn apresentou, já na década de 1970, uma grande contribuição na sua obra Class and Conformity, datada de 1977, tentando compreender os valores parentais (aqueles pelos quais os pais se orientam) e os filiais (aqueles que seus filhos adotam). Em seu estudo, definiu 13 valores parentais, que se agrupam em duas dimensões: autodireção (agir com base no seu próprio julgamento) e conformidade (agir com base nas consequiências externas).

Também nos anos 1970, Kohn (1977) referia-se a valores parentais como aqueles que os pais e mães aspiram que seus filhos incorporem ao seu comportamento, ou seja, as características que eles consideram mais desejáveis para internalizar em suas crianças. Entretanto, encontramos na literatura mais atualizada um conceito semelhante, porém definindo metas parentais. Estas seriam qualidades que os pais e mães gostariam de ver seus filhos desenvolverem ou demonstrarem em determinadas situações (Ceballos \& Rodrigo, 1998; Rodrigo, Janssens, \& Ceballos, 1999; Schulze, Harwood, \& Schoelmerich, 2001;).

$\mathrm{Na}$ tentativa de uma definição mais afinada, Tornaria, Vandemeulebroecke e Colpin (2001) sustentam que os valores são os aspectos mais abstratos das metas educativas e se referem a características que têm alto grau de estabilidade. Já as metas seriam as condutas que os pais pretendem alcançar em uma situação educativa específica, apoiadas por um(ns) valor(es). Com base nisso, Ceballos e Rodrigo (1998) identificaram quatro metas de socialização: sociabilidade, autogestão, evitação de riscos/fracassos e conformidade.

Nessa perspectiva, então, um valor é o que embasa, sustenta e direciona uma meta, pois, conforme Schwartz (1992, 1994), os valores são conceitos ou crenças que guiam o comportamento das pessoas, mas transcendem situações específicas. A meta é mais concreta e está presente nas estratégias educativas que os pais e mães utilizam para alcançar o que desejam para seus filhos.

No que se refere às estratégias educativas, encontramos divergências entre alguns autores, existindo referência a termos como estilos, estratégias e práticas educativas. São chamadas de práticas educativas as estratégias e técnicas utilizadas pelos pais e mães para orientar o comportamento de seus filhos, tentando atingir objetivos específicos em determinadas situações. Por isso, também são denominadas por alguns autores de estratégias educativas ou de socialização, uma vez que têm como função comunicar à criança o desejo do pai e da mãe de que ela modifique seu comportamento (Alvarenga \& Piccinini, 2001; Darling \& Steinberg, 1993; Hart, Nelson, Robinson, Olsen, \& McNeilly-Choque, 1998; Rodrigo, Janssens, \& Ceballos, 1999).

Hoffman $(1975,1994)$ define duas categorias de estratégias educativas: as indutivas e as coercitivas. As estratégias indutivas caracterizam-se por práticas que indicam à criança as conseqüências do seu comportamento para as outras pessoas, fazendo-a refletir sobre os aspectos lógicos da situação. A indução é um meio de controle mais indireto, que enfatiza as consequiências negativas do dano causado a outros, incentivando a empatia com estes. Práticas desse tipo favorecem a internalização de padrões morais, uma vez que propiciam à criança a compreensão dos motivos que justificam a necessidade da mudança de comportamento.

Já as estratégias coercitivas envolvem técnicas disciplinares que utilizam a aplicação de força e poder dos progenitores, incluindo punição física, ameaças e 
privação de privilégios e afetos. Essas práticas educativas não levam a criança a adquirir capacidade de compreender as implicações de sua ação, provocando um controle do seu comportamento baseado apenas na ameaça de sanções externas. É um modo de controle mais direto, que não desenvolve na criança uma motivação intrínseca para agir de determinada maneira, a não ser para evitar o castigo.

Outra terminologia encontrada na literatura para a descrição de tais construtos é estilo parental. Baumrind (1965, 1971) foi pioneira na realização de pesquisas sobre este tema, estudando os efeitos das práticas de socialização no desenvolvimento das crianças. Os estilos parentais se referem a uma tendência global de comportamento, pois os pais e as mães não agem da mesma forma com todos os filhos em todas situações (Ceballos \& Rodrigo, 1998).

Podemos, então, definir estilos educativos como tendências relativamente estáveis através das quais as pessoas reagem em uma situação pedagógica com uma determinada conduta (ou prática) específica dirigida à criança. Assim, entendemos que o estilo implica em mais do que uma conduta: é o conjunto de determinadas condutas. Desta forma, o estilo e a prática educativa estão normalmente associados, uma vez que o conjunto das práticas vai formar o estilo parental (Tornaría \& cols., 2001).

Os estudos de Baumrind $(1965,1971)$ sobre essa temática resultaram na definição de três estilos educativos: autoritário, democrático e permissivo. No estilo permissivo há pouco controle parental, os pais e mães usam poucos castigos e se mostram tolerantes, tendendo a aceitar positivamente os impulsos da criança e deixando-a regular suas atividades; no entanto, geralmente são afetivos, comunicativos e receptivos com seus filhos.

O estilo autoritário é característico de pais e mães que possuem altos níveis de controle. Eles mantêm um controle restritivo e impositivo sobre a conduta dos filhos, fazendo uso de castigos físicos, ameaças e proibições. Exercem níveis altos de exigência, não levando em consideração as necessidade e opiniões da criança e mantendo pouco envolvimento afetivo. Tendem a enfatizar a obediência através do respeito à autoridade e à ordem, além de não valorizarem o diálogo e a autonomia.

No que se refere ao estilo democrático, há um equilíbrio entre afeto e controle. Os pais reconhecem e respeitam a individualidade dos filhos, tendem a promover os comportamentos positivos do filho mais do que restringir os não desejados, mas deixam claras as normas e os limites, caracterizando um controle-guia. A disciplina é aplicada de maneira indutiva, a comunicação é clara e baseada no respeito mútuo. Este estilo está mais fortemente relacionado a uma série de aspectos do desenvolvimento psicológico de crianças e adolescentes tidos como positivos quando comparados aos demais estilos, como maturidade psicossocial, competência psicossocial, desempenho escolar, autoconfiança e menores níveis de problemas de comportamento (Dornbusch, Ritter, Leiderman, Roberts, \& Fraleigh, 1987; Lamborn, Mounts, Steinberg, \& Dornbusch, 1991; Slicker, 1998; Steinberg, Elmen, \& Mounts, 1989; Steinberg, Lamborn, Darling, Mounts, \& Dornbusch, 1991).

Na década de 1980, MacCoby e Martin (1983) fizeram uma reformulação do modelo de Baumrind (1965, 1971) e redefiniram os estilos parentais em função de duas dimensões subjacentes: o controle e o afeto. Os estilos parentais que surgem como resultados desta combinação são os mesmos propostos por Baumrind, com a diferença de que o estilo permissivo foi desmembrado em dois: o negligente e o indulgente. Assim, pais e mães autoritários possuem muita exigência e pouco afeto; os democráticos fazem muita exigência, porém são envolvidos afetivamente com seus filhos; os indulgentes estabelecem pouco controle e são muito afetivos; e, por último, pais e mães negligentes são permissivos e indiferentes, com baixo grau de controle e afeto para com os filhos, o que pode estar associado a algum tipo de mau-trato.

A partir dessa tentativa de descrição e diferenciação conceitual desses construtos, podemos pensar que o processo educativo na família segue a seguinte lógica:

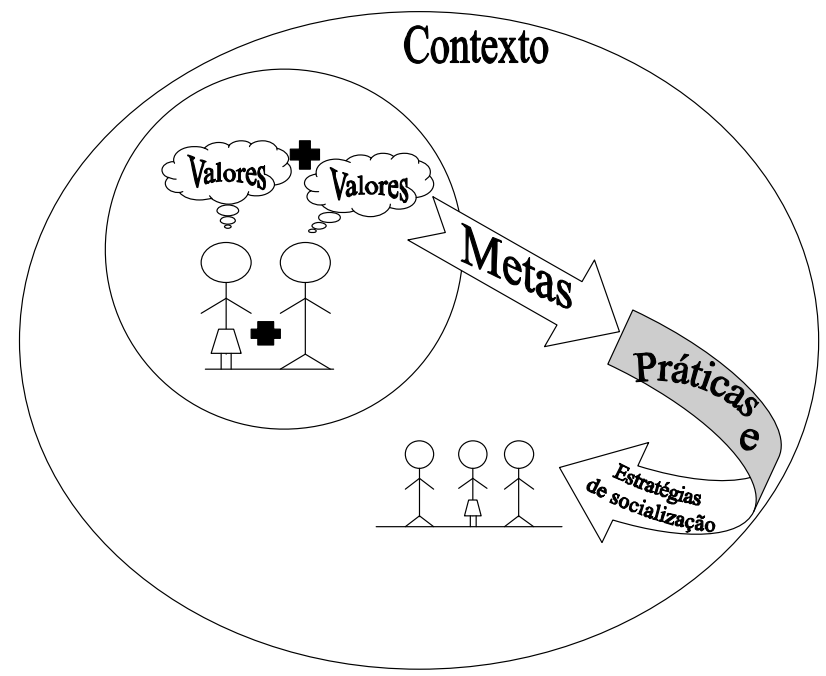

Figura 1. Processo de construção das práticas/estratégias de socialização

Os pais e as mães possuem determinados valores que querem ver desenvolvidos em seus filhos. Esses 
valores embasam suas metas educativas. Para verem estas realizadas nos filhos, eles utilizam determinadas práticas (ou estratégias) de socialização, as quais compõem seu estilo educativo. Portanto, na maioria das vezes, a maneira como os pais e mães agem com os filhos não é simplesmente improvisada.

Vários estudos têm comprovado essa premissa, afirmando que a seleção das estratégias educativas está guiada pela metas, as quais são embasadas pelos valores parentais. Ceballos e Rodrigo (1998) associam o uso de procedimentos restritivos do comportamento infantil às metas de evitação de riscos/fracassos e conformidade, enquanto a utilização de práticas indutivas aparece relacionada com a meta de sociabilidade e as práticas permissivas normalmente se apresentam associadas à meta de autogestão.

Podem-se corroborar tais supostos em uma pesquisa realizada na Holanda (Rispens, Hermanns \& Meeus, citado por Tornaría \& cols., 2001), com 1267 famílias, na qual se observaram relações entre algumas metas e estratégias educativas. Por exemplo, progenitores que enfatizavam a autonomia como uma meta importante informaram o uso mais freqüente de condutas do tipo democrático (ou indutivo) do que do tipo autoritário (ou coercitivo).

Com relação aos valores parentais, um estudo realizado por Luster, Rhoades e Haas (1989) concluiu que tais valores também se manifestam através das estratégias educativas. Esta pesquisa apontou que pais e mães que valorizam a autodireção, além de enfatizarem a responsabilidade, acreditam que usar estratégias com poucas restrições às crianças favorece a liberdade para a exploração do ambiente. Ao contrário, pais e mães que valorizam a conformidade estão mais propensos a dar ênfase a estratégias restritivas e repressivas aos comportamentos aversivos, acreditando que a educação efetiva envolve disciplina e controle.

Embora não haja dúvida quanto a estas relações, acreditamos que existam outros fatores também capazes de influenciar o uso de determinada prática em uma situação educativa, por exemplo, aspectos relacionados com a idade, o temperamento da criança e o gênero, este aqui entendido como a construção social do papel de homens e mulheres, considerando os aspectos relacionais e culturais como referência a qualquer construção social que tenha a ver com a distinção masculino/feminino, de acordo com SallesCosta, Heilborn, Werneck, Faerstein e Lopes (2003). Também devem ser considerados a situação, o local e o contexto do evento. Nesse caso, é provável que um pai estressado por problemas no trabalho não vá agir da mesma maneira como agiria se estivesse tranqüilo. $\mathrm{O}$ fato de o evento que demanda uma intervenção educativa estar ocorrendo em casa, na rua ou no vizinho também é fator importante na escolha da conduta a ser tomada.

Nesse sentido, Pearson e Rao (2003) comprovaram que as estratégias educativas são afetadas também pelo contexto no qual ocorrem (situacional, familiar e cultural). Rodrigo, Janssens e Ceballos (1999) exemplificam dizendo que um comportamento agressivo da criança eliciaria estratégias de coerção, enquanto a violação de uma norma social eliciaria o uso de uma estratégia indutiva. Isso indica que a eleição de uma determinada estratégia pode variar, também, de acordo com a natureza do comportamento da criança.

Se partirmos do pressuposto de que, ao agirem com os filhos, os pais e mães possuem uma intenção, poderíamos então imaginar que bastaria eles utilizarem determinadas práticas para verem suas metas educativas desenvolvidas em seus filhos. Entretanto, não é o que ocorre. Neste sentido, Hernández e cols.. (1998) reconhecem que não podemos afirmar a existência de uma relação direta entre os valores e as metas que os pais e mães desejam para seus filhos e os que os filhos adquirem. Entendem que a adoção e interiorização de valores pelas crianças não resultam apenas da imitação dos valores de seus pais, e sim, são fruto de um processo construtivo no qual a criança, em relação com outras pessoas, vai dar sentido à realidade social que a rodeia. Cada criança vai dar um sentido e interpretar as condutas de seus progenitores conforme suas experiências e contexto, e por isto, seus valores poderão ser similares aos paternos, mas nunca idênticos. Dentro desta ótica, os filhos são agentes ativos no processo de construção de valores.

Então, é preciso explorar o que é necessário para que os pais e mães consigam transmitir os valores que consideram importantes. Ceballos e Rodrigo (1998) afirmam que não existe, a priori, um procedimento mais eficaz, ou uma receita educativa infalível para transmitir valores e alcançar as metas educativas. $\mathrm{Na}$ educação, o importante é ser flexível, aplicando distintas estratégias, de acordo com a situação, a idade da criança e o estilo do seu comportamento. Isto traduz a complexidade da tarefa parental de educar os filhos, a qual exige constante esforço, principalmente quando entendemos que o desenvolvimento infantil recebe influências diferenciadas dos diversos contextos dos quais a criança participa.

A partir desta perspectiva, iluminada pelos pressupostos da teoria ecológico-sistêmica de 
Bronfenbrenner, entendemos que o sujeito está em estreita união com o ambiente no qual está inserido, transformando e sendo transformado na relação que aí se estabelece (Bronfenbrenner, 1979/1996). Assim, podemos pensar que os pais e mães, ao construírem seus valores, metas e estratégias educativas, fazem-no através da interação com seu contexto sociocultural; ou seja, esta construção se processa com interdependência dos vários aspectos do meio em que vivem.

Desde estes pressupostos, diferentes pesquisas têm sido feitas no sentido de definir as variáveis presentes na construção dos valores, metas e estratégias educativas que caracterizam as famílias (Palácios \& Rodrigo, 1998). Atualmente não se trabalha mais com a perspectiva de um modelo unidirecional no processo de transmissão de valores e metas. Postula-se que exista uma aprendizagem recíproca, na qual o indivíduo, a família e a sociedade interagem e trocam informações necessárias ao desenvolvimento e adaptação ao meio (Hoffman, 1994; Martins \& Branco, 2001; Pearson \& Rao, 2003).

De acordo com a literatura e pesquisas empíricas sobre socialização infantil, a realidade social, política, econômica e cultural influencia a maneira como as pessoas hierarquizam os valores para educar um filho. Acredita-se, da mesma maneira, que existe uma relação entre os valores educativos e classes sociais. Tudge, Hogan, Snezhkova, Kulakova e Etz (2000b) afirmam que, embora estes fatores do contexto, que pertencem ao nível macrossistêmico, não sejam suficientes para explicar os valores e as metas parentais, é certo que possuem um importante papel na sua determinação.

Com essa mesma compreensão, Kohn (1976, 1977) realizou uma série de estudos relacionando os valores parentais com a classe social, considerando o nível socioeconômico-cultural dos sujeitos implicados. Sua conclusão central é que o nível socioeconômico é uma variável significativa para o comportamento humano, porque abrange condições de vida diferenciadas, que afetam profundamente a visão do homem sobre a realidade social. Dando mais suporte a este raciocínio, ainda encontrou que as condições ocupacionais dos pais e mães respondem por grande parte do impacto do nível socioeconômico nos valores e orientações transmitidos aos filhos.

Seus estudos demonstraram que pais e mães pertencentes a níveis sociais mais elevados, com maior escolaridade, poder aquisitivo, etc., tenderiam a priorizar valores de autodireção nas crianças (autocontrole, responsabilidade, curiosidade, etc.), enquanto famílias de nível socioeconômico inferior, com menor escolaridade, poder econômico, etc. se preocupariam mais com valores de conformidade (limpeza, bons modos, obediência, etc.). Os estudos de Curtner-Smith, Bennett e O’Rear (1995), Ispa (1995), Luster, Rhoades e Haas (1989), Tudge, Hogan, Snezhkova, Kulakova e Etz (2000b) e Xiao (2000) também confirmam esta relação.

Ainda que bastante questionadas atualmente, reflexões feitas por Kohn nos anos 1970 (1976, 1977) apontam uma tendência de que estas preferências surgem em pais e mães de nível socioeconômico médio que enfatizam a importância de os filhos seguirem padrões internos para suas condutas (autodireção), enquanto os de nível socioeconômico baixo preocupamse mais com a adesão a padrões externos de comportamento (conformidade).

Esta tendência das famílias de menor nível socioeconomico-cultural de valorizar mais a conformidade pode ser decorrente da sua adesão do senso comum construído de que o pobre é um necessitado, portanto, deve sempre obedecer e respeitar as hierarquias e aceitar as situações que lhe são impostas. Telles (1990) faz uma crítica e esclarece esse pensamento afirmando que a prática de estigmatização e criminalização desses níveis sociais se ancora num imaginário social de cidadania, o qual exclui a liberdade pública como valor político, que se confunde com o respeito à ordem e à autoridade, de tal forma que as reivindicações e demandas coletivas sempre estão nas fronteiras daquilo que é percebido como transgressão, como desordem. Sendo assim, é necessário cautela na adesão a tais idéias, considerando-se que outras leituras, como aquelas feitas desde a Antropologia, por exemplo, ajudam a pensar as diferenças de classe e os universos simbólicos, desconstruindo a linearidade dessa relação.

Além das pesquisas que relacionam os valores e metas educativas com variáveis socioeconômicoculturais, também se tem tentado identificar em que medida estas variáveis estão relacionadas com a escolha das estratégias educativas. Um dos fatores que aparecem com maior frequiência nesta eleição é justamente o nível socioeconômico dos sujeitos implicados. Ceballos e Rodrigo (1998) indicam que os pais e mães de nível médio e alto fazem mais uso de estratégias indutivas; já os pais e mães de nível baixo utilizam mais sistematicamente estratégias baseadas na afirmação de poder, que supõem o uso de castigos físicos, ameaças e uso de técnicas coercitivas.

Não obstante, é preciso ter cautela com esta afirmação, pois corremos o risco de cair no velho 
preconceito de que apenas as famílias de níveis sociais mais populares agridem fisicamente seus filhos, por exemplo, como se isso não ocorresse em outras camadas sociais. Sabemos que as agressões também ocorrem nos níveis socioeconômicos mais elevados, porém estão mais encobertas, mais veladas, e muitas vezes dão-se em forma de pressão psicológica, a qual não é visível fisicamente, a olho nu. Wagner (1995), em um estudo sobre medos infantis, constatou que pais e mães de nível socioeconômico médio tendem a dar mais respostas de desejabilidade social no que se refere às estratégias educativas utilizadas com seus filhos, isto é, camuflam, muitas vezes, o uso de estratégias coercitivas com seus filhos. O fato de terem mais acesso à informação e melhores níveis de escolaridade faz com que tenham consciência de como devem interagir na relação pais-filhos, entretanto, esse conhecimento não garante que estabeleçam uma relação menos coercitiva no exercício da parentalidade

De qualquer forma, o que queremos ressaltar é que os valores e as metas que os pais e as mães desejam para seus filhos, as estratégias que utilizam para a transmissão desses valores e metas e a própria forma de pensar com relação ao desenvolvimento e educação das crianças se constroem sobre marcos de referência preexistentes na cultura e na sociedade em que vivem e no grupo social ao qual pertencem (Palácios, Moreno \& Hidalgo, 1998). Assim, fica evidente a necessidade de aproximação do ambiente no qual os estudos sobre esta temática acontecem, pois a inter-relação entre o fenômeno e o contexto é inegável.

\section{FAMÍLIAS DE BAIXO NÍVEL SOCIOECONÔMICO}

O modelo capitalista tem se caracterizado nos países do Terceiro Mundo pelo declínio alarmante das condições de vida das suas populações (Hita, 1997). O processo de urbanização, as migrações, a formação do proletariado, as modernas condições femininas de vida e de trabalho, a má distribuição de renda são alguns fatores que têm contribuído para esse processo. Hoje em dia, de acordo com os dados levantados pelo Censo 2000 (Instituto Brasileiro de Geografia e Estatística) tem havido um crescimento da população economicamente desfavorecida em $2,8 \%$, enquanto a classe média brasileira encolheu 5,78\%. Essas evidências expressam a relevância de estudos que contemplem as camadas menos favorecidas da população brasileira.

O conceito de pobreza é bastante complexo e apresenta diferentes definições e parâmetros de análise.
A maioria dos indicadores de pobreza em nosso país refere-se à renda, sendo muito utilizadas medidas como linhas de pobreza. Entretanto, a condição de pobreza pode ser definida como um fenômeno multidimensional e diverso, incluindo aspectos culturais, sociais e econômicos, que se caracterizam por: exclusão e discriminação devido à origem étnica ou ao gênero; carência ou acesso limitado a serviços destinados a satisfazer as necessidades básicas da família; níveis de renda inferiores à quantidade mínima para obter um conjunto básico de bens e serviços para a família e frágeis condições de saúde e educação (Comim \& Bagolin, 2002; Waquil \& Mattos, 2003).

Todas estas dimensões que caracterizam as famílias de nível socioeconômico baixo afetam diretamente seu modo de ser e de viver, conferindo algumas peculiaridades na organização dos núcleos familiares que vivem nestas condições. Hita (1997) afirma que, pelo fato de os grandes modelos teóricos reduzirem e homogeneizarem as diferentes manifestações e formas de ser de cada grupo social, sempre existem as tendências-padrão. No caso de famílias brasileiras de baixo nível socioeconômico baixo, podemos sugerir uma caracterização geral baseada nas informações hoje disponíveis.

Ainda que tenha havido uma redução das famílias numerosas entre os setores de baixa renda, especialmente os urbanos, o arranjo doméstico mais comum ainda é deste tipo, no qual existe mais de um núcleo familiar ou inclusão de outros parentes (como avós, tios, primos). Isto é decorrente, em grande parte, do desemprego, dos baixos salários e da instabilidade das relações conjugais. Há baixos percentuais de pais trabalhando e as mães acabam assumindo a responsabilidade do sustento da família, aparecendo, cada vez com mais freqüência, os núcleos chefiados por mulheres (Amazonas, Damasceno, Terto, \& Silva, 2003; Oliveira \& Bastos, 2000; Hita, 1997; Sarti, 2003; Woortmann, 1987).

A organização doméstica baseada na divisão tradicional de papéis, sendo o homem o provedor econômico e a mulher a cuidadora da casa, dos filhos e do marido, aparece muito mais como um ideal a ser perseguido do que como uma realidade vivenciada (Amazonas, Damasceno, Terto, \& Silva, 2003), já que cada vez mais é a mulher quem se encarrega do sustento das famílias.

Embora a mulher apareça como uma figura central, estudos recentes sobre os pobres urbanos mostram que nessas famílias ainda prevalecem os valores tradicionais e padrões patriarcais de hierarquia, reafirmando a autoridade masculina. Isto 
quer dizer que quando não há um homem em casa, ou quando este está desvalorizado devido a determinada circunstância, a família pode ficar fragilizada socialmente (Sarti, 2003).

Frente a esta situação, aliada às freqüentes rupturas dos vínculos conjugais e da instabilidade do trabalho, estas famílias necessitam desenvolver maneiras de sobrevivência que favoreçam o desenvolvimento de seus membros. Por isso, é comum que recorram a sua rede familiar mais ampla e aos vizinhos, formando, por vezes, uma rede de solidariedade.

Ainda que esta rede de solidariedade nem sempre aconteça, quando se materializa é um recurso fundamental para que as famílias de classe popular possam enfrentar sua condição social e garantir sua sobrevivência diante de um contexto que oprime seu desenvolvimento. É uma lógica que se opõe ao individualismo característico da nossa sociedade, reordenando valores e subordinando realizações pessoais a necessidades do grupo familiar (Amazonas, Damasceno, Terto, \& Silva, 2003; Llanos, Orozco \& García, 1999). Estas famílias aderem a um código moral distinto daquele que norteia a lógica do mercado, vigente na sociedade capitalista, criando outras referências positivas para quem é visto pela sociedade mais ampla como destituído. Assim, o trabalho e a família constituem as referências básicas através das quais os pobres constroem uma identidade social positiva (Sarti, 2003). Portanto, o trabalho e a família assumem uma posição central na vida destas pessoas, pois são os espaços que lhes conferem certa noção de ordem, dignidade e auto-estima.

Com relação à educação das crianças, existe uma forte hierarquia entre progenitores e filhos, e a educação é concebida como exercício unilateral da autoridade. O respeito aos mais velhos, em especial aos pais, é um valor fundamental, ancorado na obediência, mas, principalmente, caracterizado pelo não-desafio à autoridade dos pais (Hita, 1997; Sarti, 2003). Além disso, as crianças começam a ter atribuições e obrigações familiares desde pequenas. Muitas têm o dever de cuidar da casa e dos irmãos mais novos quando os pais e as mães saem para trabalhar, assumindo responsabilidades desde muito cedo.

Outra característica dessas famílias apontada por Amazonas, Damasceno, Terto e Silva (2003) refere-se à indiferenciação entre o público e o privado. A rua passa a ser uma extensão da casa, muitas vezes em conseqüência das condições precárias da moradia, que é quente, pequena e desconfortável. Isso faz com que estas famílias passem muito tempo em convívio com a comunidade. Não obstante, vem sendo questionada a manutenção da lógica binária, que utiliza a polaridade público $\mathrm{X}$ privado na leitura do comportamento dessa camada da população. Provavelmente, a classe média é bastante mais ciosa de seu espaço de intimidade, pois modos de viver correspondem a modos de subjetivar; assim, longe de romantizar a pobreza, não se trata aqui de demonizá-la, inclusive quanto à separação entre público e privado. Nesse caso, não somente as condições de moradia são responsáveis pela forma de limitar os espaços: uma análise mais apurada nos indica que são modos diferentes de relacionar-se com o contexto.

\section{CONSIDERAÇÕES FINAIS}

O modelo de organização familiar preponderantemente característico da classe média tem sido freqüentemente utilizado na literatura como um padrão e um parâmetro ao avaliar-se a diversidade de organizações familiares. Quando isto ocorre, é bastante comum verificarmos que as diferenças que aparecem na comparação com este modelo são interpretadas, na maioria das vezes, como déficits de funcionamento daquelas famílias que não se organizam de tal forma. É fácil cair nessa armadilha se, ao pesquisarmos famílias, não considerarmos seu contexto socioeconômico-cultural.

Apesar de estarmos vivendo na era da globalização, na qual existe uma tendência à busca das semelhanças, fazendo com que as diferenças sejam cada vez mais difusas e os padrões de funcionamento cada vez mais homogêneos, podemos perceber que há certas peculiaridades na forma como as famílias de classes populares se estruturam e se organizam.

No que se refere, especificamente, à educação familiar, as diferenças entre os níveis socioeconômicos aparecem a partir do desejo de pais e mães de educar seus filhos de forma que estes desenvolvam competências que satisfaçam as necessidades culturais de seu contexto, e assim adaptam suas estratégias educativas para atender a tais expectativas; ou seja, os pais e as mães ensinam a seus filhos as competências necessárias para viver em seu ambiente físico e cultural. Esse é um processo que garante a perpetuação a partir da transmissão, de uma geração à outra, de valores e crenças. Assim, as estratégias educativas funcionam como um instrumento e ajudam a fazer os ajustes necessários frente às contingências e demandas do contexto.

Partir do pressuposto de que o nível socioeconômico e o contexto estão implicados diretamente na construção da parentalidade é superar a 
distorção de que as diferenças encontradas são devidas a déficits ou desvios. O importante é que possamos pensar nas idiossincrasias do meio em que vivem as famílias de camadas populares, pois elas refletem e são refletidas nos padrões de interação que se estabelecem nessa população.

Nesse caso, pensamos que pesquisar as famílias brasileiras que encerram tal pluralidade leva a uma incursão pelos trabalhos brasileiros, em especial os que estabelecem um diálogo extremamente profícuo com outras áreas - como a Antropologia, a Educação e a Saúde - a fim de que se possa abranger mais amplamente a complexidade do tema.

De outro modo, torna-se incoerente e pode fazer cair no reducionismo da lógica do "déficit" enfatizarmos as influências do meio sociocultural no processo de socialização infantil partindo de teorias e pressupostos que não alcancem explicar a nossa realidade. Eis aí um grande desafio para os pesquisadores interessados em conhecer as peculiaridades das famílias brasileiras.

\section{REFERÊNCIAS}

Alvarenga, P. \& Piccinini, C. (2001). Práticas educativas e problemas de comportamento em pré-escolares. Psicologia: Reflexão e Crítica, 14(3), 449-460.

Amazonas, M. C. L. A., Damasceno, P. R., Terto, L. M. S., \& Silva, R. R. (2003). Arranjos familiares de crianças de camadas populares. Psicologia em Estudo, 8, Especial., 11-20.

Baumrind, D. (1965). Parental control and parental love. Children, 230-234.

Baumrind, D. (1971). Current patterns of parental authority. Developmental Psychology Monograph, 4(1/2), 1-103.

Bronfenbrenner, U. (1996). A ecologia do desenvolvimento humano: experimentos naturais e planejados. Porto Alegre: Artes Médicas (Original publicado em 1979).

Ceballos, E. \& Rodrigo, M. J. (1998). Las metas y estrategias de socialización entre padres e hijos. En M. J. Rodrigo \& J. Palácios (Eds.), Familia y desarrollo humano. (pp.225243). Madrid: Alianza editorial.

Comim, F. \& Bagolin, I. (2002). Aspectos qualitativos da pobreza no Rio Grande do Sul. Ensaios FEE, 23, Especial, 467-490.

Curtner-Smith, M. E., Bennett, T. L., \& O’Rear, M. R. (1995). Fathers' occupational conditions, values of self-direction and conformity, and perceptions of nurturant and restrictive parenting in relation to young children's depression and aggression. Family relations, 44, 299-305.

Darling, N. \& Steinberg. L. (1993). Parenting style as a context: an integrative model. Psychological Bulletin, 113(3), 487-496.

Dornbusch, S. M., Ritter, P. L., Leiderman, P. H., Roberts, D. F., \& Fraleigh, M. J. (1987). The relation of parenting style to adolescent school performance. Child Development, 57, 879-894.

Hart, C. H., Nelson, D., Robinson, C. C., Olsen, S. F., \& McNeilly-Choque, M. K. (1998). Overt and relational aggression in Russian nursery-school-age children: Parenting style and marital linkages. Developmental Psychology, 34, 687-697.

Hernandéz, M. D. G., Rodríguez, G. R., \& Zamora, A. L. (1998). La construcción de valores em la família. In M. J. Rodrigo \& J. Palácios (Eds.), Familia y desarrollo humano. (pp. 201-221). Madrid: Alianza editorial.

Hita, M. G. (1997). Família e pobreza: modelo único ou hegemônico? Población y Cambio Social. Revista Latinoamericana de Población, 1(1). Disponível em <http://www.unam.mx/prolap/hita4.html>. (Acesso em 23/10/2004).

Hoffman, M. L. (1975). Moral internalization, parental power, and the nature of parent-child interaction. Developmental Psychology, 11, 228-239.

Hoffman, M. L. (1994). Discipline internalization. Developmental Psychology, 30, 26-28.

Ispa, J. M. (1995). Ideas about infant and toddler among Russian child care teachers, mothers, and university students. Early Childhood Research Quarterly, 10, 359379

Instituto Brasileiro de Geografia e Estatística. Censo 2000. Disponível em 〈http://www.ibge.org.br〉. (Acesso em $11 / 11 / 2004)$

Kohn, M. (1976). Social class and parental values: another confirmation of the relationship. American Sociological Review, 41, 538-548.

Kohn, M. (1977). Class and conformity. Chicago: University of Chicago Press.

Lamborn, S. D., Mounts, N. S., Steinberg, L., \& Dornbusch, S. M. (1991). Patterns of competence and adjustment among adolescents from authoritative, authoritarian, indulgent, and neglectful families. Child Development, 62, 10491065.

Llanos, R. A., Orozco, C. M., \& Garcia, O. S. (1999). Relationship between the social networks and the family dynamics of low-income working women. Journal of Community Psychology, 27(3), 243-255

Luster, T., Rhoades, K., \& Haas, B. (1989). The relation between parental values and parenting behavior: A test of the Kohn hypothesis. Journal of Marriage and the Family, 51, 139-147.

MacCoby, E. E. (1984). Socialization and developmental change. Child Development, 55, 317-328.

MacCoby, E. \& Martin, J. (1983). Socialization in the context of the family: Parent-child interaction. In E. M. Hetherington (Ed.), P. H. Mussen (Org. Série), Handbook of child psychology ( Vol. 4: Socialization, personality, and social development, (4 $4^{\mathrm{a}}$ ed., pp. 1-101). New York: Wiley.

Martins, C. L. \& Branco, U. A. (2001). Desenvolvimento moral: considerações teóricas a partir de uma abordagem sociocultural construtivista. Psicologia: Teoria e Pesquisa, $17(2), 1-14$. 
Oliveira, M. L. S. \& Bastos, A. C. S. (2000). Práticas de atenção à saúde no contexto familiar: um estudo comparativo de casos. Psicologia: Reflexão e Crítica, 13(1), 97-107.

Palácios, J., Moreno, M. C. \& Hidalgo, M. V. (1998). Ideologias familiares sobre el desarrollo y la educación infantil. In M. J. Rodrigo \& J. Palácios (Eds.), Familia y desarrollo humano. (pp.181-200). Madrid: Alianza.

Palácios, J. \& Rodrigo, M. J. (1998). La familia como contexto de desarrollo humano. In M. J. Rodrigo \& J. Palácios (Eds.), Familia y desarrollo humano (pp.25-44). Madrid: Alianza editorial.

Pearson, E. \& Rao, N. (2003). Socialization goals, parenting practices, and peer competence in chinese and english preschoolers. Early Child Development and Care, 173(1), 131-146.

Rodrigo, M. J., Janssens, J. M. A. M., \& Ceballos, E. (1999). Do children's perceptions and attributions mediate the effects of mothers' child-rearing actions? Journal of Family Psychology, 13(4), 508-522.

Rokeach, M. (1973). The nature of human values. New York: Free Press.

Salles-Costa, R., Heilborn, M. L., Werneck, G. L., Faerstein, E., \& Lopes, C. S. (2003). Gênero e prática de atividade física de lazer. Cadernos Saúde Pública, 19(2), 325-333. Disponível em <http://www.scielo.br>. (Acesso em 12/02/2006).

Sarti, C. A. (2003). A família como espelho: um estudo sobre a moral dos pobres. São Paulo: Cortez.

Schulze, P., Harwood, R. L. \& Schoelmerich, A. (2001). Feeding practices and expectations among middle-class Anglo and Puerto Rican mothers of 12 months old infants. Journal of Cross-Cultural Psychology, 32(4), 397-406.

Schwartz, S. H. (1992). Universal in the content and structure of values: theoretical advances and empirical tests in 20 countries. In M. Zana (Ed.), Advances in experimental social psychology (Vol. 25, pp.1-65). Orlando: Academic Press.

Schwartz, S. H. (1994). Are there universal aspects in the structure and contents of human values? Journal of Social Issues, 50(4), 19-45.

Slicker, E. K. (1998). Relationship of parenting style to behavioral adjustment in graduating high school seniors. Journal of Youth and Adolescence, 27, 345-372.
Smith, T. E. (1982). The case for parental transmission of educational goals: the importance of accurate offspring perceptions. Journal of Marriage and the Family, 44, 661674.

Steinberg, L., Elmen, J., \& Mounts, N. (1989). Authoritative parenting, psychosocial maturity, and academic success among adolescents. Child Development, 60, 1424-1436.

Steinberg, L., Mounts, N. S., Lamborn, S. D., \& Dornbusch, S. M. (1991). Authoritative parenting and adolescent adjustament across varied ecological niches. Journal of Research on Adolescence, 1(1), 19-36.

Telles, V. S. (1990). A pobreza como condição de vida: Família, trabalho e direitos entre as classes trabalhadoras urbanas. São Paulo em Perspectiva, 4, 37-45.

Tornaria, M. L. G., Vandemeulebroecke, L. \& Colpin, H. (2001). Pedagogía familiar. Montevideo: Trilice.

Tudge, J., Hayes, S., Doucet, F., Kulakova, N., Tammeveski, P., Meltsas, M., \& Lee, S. (2000a). Parent's participation in cultural practices with their preschoolers. Psicologia: Teoria e Pesquisa, 16(1), 1-10.

Tudge, J., Hogan, D. M., Snezhkova, I. A., Kulakova, N. N., \& Etz, K. E. (2000b). Parent's child-rearing values and beliefs in the Unites States and Russia: The impact of culture and social class. Infant and Child Development, 9, 105-121.

Wagner, A. (1995). Os fatores psicossociais do medo infantil: sua ocorrência e características na idade pré-escolar. Psico, 26(1), 89-106.

Waquil, P. D. \& Mattos, E. J. (2003). Distribuição de renda no Rio Grande do Sul: um comparativo entre o rural e o urbano. Ensaios FEE, 23, Especial, 621-644.

Woortmann, K. (1987). A família das mulheres. Rio de Janeiro: Tempo Brasileiro/CNPq.

Xiao, H. (2000). Structure of child-rearing values in urban China. Sociological perspectives, 43(3), 457-471.

Recebido em 01/07/2005 Aceito em 03/02/2006

Endereço para correspondência: Adriana Wagner. Av. Ipiranga n. 6681, prédio 11, sala 931, CEP 90619-900, Porto AlegreRS. E-mail: wagner@pucrs.br 